\title{
Numerical Modeling of Explosive Loading on Strong Rock Mass with Discontinuity System in Depth $25 \mathrm{~m}$
}

\author{
Nabi Nakhaei*, Mohsen Jami, Homan Najafizade, Farhad Jahani Adimi, \\ Seyed Hossein Mirzeinaly Yazdi, Mohsen Pourkermani, Nazanin Sarhadi \\ Department of Geology, Zahedan Branch, Islamic Azad University, Zahedan, Iran \\ Email: *Nabi.Nakhaei@GMail.com
}

Received 11 December 2015; accepted 4 March 2016; published 7 March 2016

Copyright @ 2016 by authors and Scientific Research Publishing Inc.

This work is licensed under the Creative Commons Attribution International License (CC BY). http://creativecommons.org/licenses/by/4.0/

(c) (i) Open Access

\begin{abstract}
Effect of Explosion on underground structures where drilled on the stony materials can be affected by explosive strength and rock mass properties of tunnel. In this paper, it has been studied on effect of explosion of 10 tons TNT on the round tunnel (diameter: $10 \mathrm{~m}$ ) in $\mathbf{2 5} \mathbf{m}$ depth in the mass rocks (RMR > 90) to estimate stability of tunnel to construct underground structure. Regarding to the studied stones, geo-mechanical indices of rock mass have been found to use as strength criteria in UDEC. In the next step, tunnel in real dimensions and founded indices is modeled with UDEC and analyzed stably. Explosion wave indices are found by UFC Instruction and other experimental relations to administer force from explosion wave on the model. Finally, on the base of FISH, indices of explosion wave are administrated in UDEC and tunnel is analyzed dynamically. According to modeling in depth of $25 \mathrm{~m}$, amount of displacement of drilled tunnel in mass rocks ( RMR < 90) is very lower than standard criterion and the tunnel is very stable. Development of plastic zone, vertical and horizontal displacement of rock mass around the tunnel, speed variations and stress from explosion wave are modeled and recorded as the graphs and figures.
\end{abstract}

\section{Keywords}

Underground Structure, Plastic Zone, Round Tunnel, UDEC Software, UFC Instruction

\section{Introduction}

Today, Passive Defense is an important case in army. Passive defense is a civil defense and refers to a series of

${ }^{*}$ Corresponding author.

How to cite this paper: Nakhaei, N., Jami, M., Najafizade, H., Adimi, F.J., Yazdi, S.H.M., Pourkermani, M. and Sarhadi, N. (2016) Numerical Modeling of Explosive Loading on Strong Rock Mass with Discontinuity System in Depth 25 m. Open Journal of Geology, 6, 117-130. http://dx.doi.org/10.4236/ojg.2016.63012 
steps to use weapons do not need to run it possible financial damage to equipment and facilities critical military and civilian casualties or the extent of the damage and prevent losses may be reduced to a minimum. One of the most important principles of Passive Defense is to construct safe structures. Some places such as unity tunnels, underground hospitals and mines can be used as the safe structures for Passive Defense. It is necessary to study on these places and estimate their stability. On the one hand, explosion waves have caused dynamical stress on rock masses around the underground places and led to failure and convergence and new forms around the rock mass that it can be covered stability of underground spaces. Then, it is necessary to study on explosion and its effects on underground structures and stability of these places from explosive loads.

The most important aims of this paper include: study on the important factors in seismic loading effect on stability of underground structures, effect of depth on the rocks with discontinuity system and analyze tunnel stability and amount of wave damping. Generally, stability of these structures against explosive loads from bombs and rockets should be studied before using them as the passive defense structures. On the one side, destroying from rocks and bomb is one of the most complex mechanical processes that it has been studied carefully during 2 centuries ago. At present, three methods can be used to evaluate these cases: finding experimental relations on the basis of repeated tests, developing simple dynamic splash methods, penetration and explosion by using laws of motion and materials and advanced numerical methods to model explosion load effects on underground structures. Methods based on experimental relations are very expensive and especial for each property. Then, they cannot be used for all conditions. Methods based on engineering models are simple with some information. They are ideal to evaluate and study on results from explosion loads. But they are not precise to analyze because of using making simple hypothesizes.

On the other side, advanced numerical methods have considered all cases and provided better results. There are some problems to use numerical methods such as need to precise input information, time to compute, high computational cost, precisely understanding solutions of problem. Because of increasing computational power of computers and saving basic information, researchers and scientists would like to use numerical methods recently.

An explosion is a rapid increase in volume and release of energy in an extreme manner, usually with the generation of high temperatures. TNT is an explosive material and it is stable and pure chemically and it can be compared with various explosive materials [1]. As mentioned above, an explosion is a rapid increase in volume and release of energy in an extreme manner. Based upon it, explosive materials have various explosive specifications regarding type and methods of combination. It consists of:

Released energy, fast explosion that fast explosion of TNT is about $2000 \mathrm{f} / \mathrm{s}$.

There are many important variables that effect on exploring rocks such as properties of stone and explosive materials and explosive patterns. Each explosion has two parameters: Pressure and Volume. Two parameters of distributing different components of energy in explosion process are shown in Figure 1.

On the basis place of exploring to the earth, Explosions can be categorized in three groups [2]:

Explosions that placed up to the earth.

Explosions that placed on the earth (model of this paper).

Explosions that placed under the earth.

\section{Background}

Sheng-tian and Zhi-yuan (1993) have described dynamic interaction of underground structures and local rocks by using Bending Equations of thick and thin plates [3]. Also, Chen and Zhao (1998) have studied on wave propagation process from explosion in discontinuous and jointed rock masses by using UDEC and AUTODYN [4]. Morris et al. 2004 have presented results from loading of tunnels placed on Nevada Site (they are placed in granite and tuff areas with maximum stresses) by using method of three dimensional separated elements [5]. Lu (2005) has studied on effect of different parameters including geological conditions and density of explosive material on explosion in Swedish tunnels and modeled these results by using Artificial Neural Network [6]. Heuze and Morrise (2006) have performed laboratory and desert tests to model effect of explosion in jointed rock mass [7]. Jiao et al. (2007) has studied on effect of wave propagation from explosion by using Discontinuous Deformation Analysis (DDA) in jointed rock mass [8]. Mortazavi (2003) has evaluated role of strength properties of discontinuities on stability of underground spaces under dynamic load by using Discontinuous Deformation Analysis [9]. Also, Mirzeynali and Bejarivalam (2011) have studied on numerical modeling of explosive loading on weak continuous rock mass by using Finite Difference Method with FLAC (A 2 Dimentional 


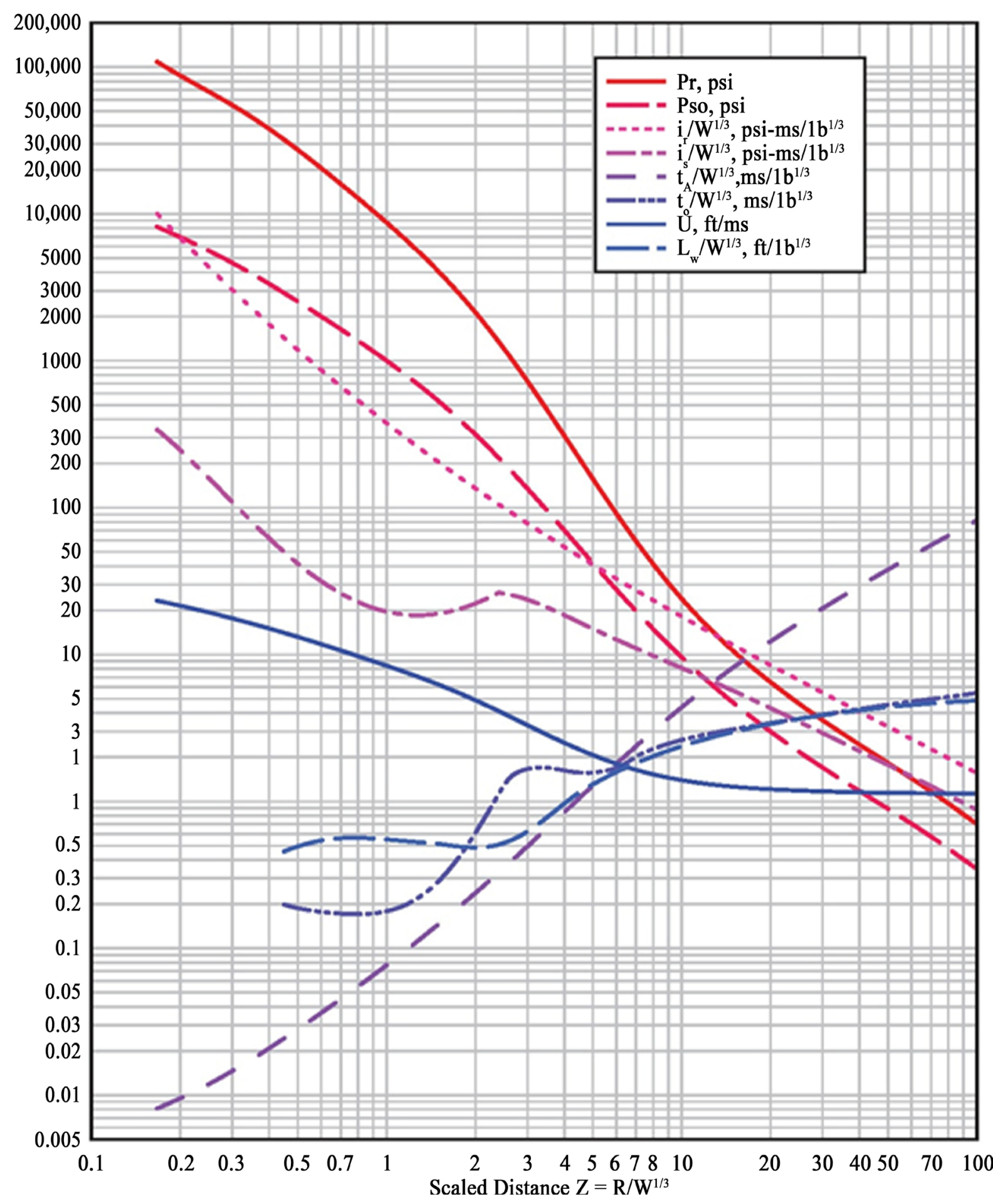

Figure 1. Computing explosion wave parameters [11].

Software) [10].

\section{Method of Computing Explosion Wave Parameters}

Today, both experimental and numerical methods can be used to compute wave parameters. In this paper, we use experimental methods and UFC Instruction [11]. 
According to UFC Instruction, Figure 1 should be used to compute wave parameters. where

$\mathrm{W}$ : weight of explosive material (on the basis of pond (Ib)).

P: Pressure from explosion (on the basis of PSI).

$\mathrm{R}$ : Distance from explosion place (on the basis of $\mathrm{ft}$.).

$\mathrm{T}$ : Time (on the basis of ms).

\section{Modeling}

This rock mass is very strong (RMR > 90). Complete Mechanical Specifications of joints and the rocks have been studied in Table 1 [2].

\subsection{Computing Wave Parameters from Explosion}

Both experimental and numerical methods have been used to compute wave specifications from exploring 10 tons TNT.

Based upon it, necessary specifications to find wave coefficients are as follow as:

Distance from Explosion Place (R): place of measuring wave parameters has been placed at a distance of 1.5 $\mathrm{m}$ from explosive material, then

$$
\mathrm{R}=1.5 \mathrm{~m} * 3.28=4.92 \mathrm{ft}
$$

Weight of Explosive Material (W): 10 tons TNT.

$$
\mathrm{W}=10000 \mathrm{~kg} * 2.2 \approx 22000 \mathrm{Ib}
$$

Then, Parameter $\mathrm{Z}$ will be computed to be used UFC Instruction that is equal to:

$$
\mathrm{Z}=\mathrm{R} / \mathrm{W}^{1 / 3} \rightarrow \mathrm{Z}=0.175
$$

At the next stage, pressure from explosion is about psi13250 that is equal to 90.1 as following:

$$
\mathrm{q}=13250 \mathrm{psi} * 0.0068 \approx 90.1 \mathrm{Mpa}
$$

Finally, refer to UFC Instruction (Figure 1) to compute Parameters of Explosive Wave.

\subsection{Tunnel Modeling by UDEC}

Parameters from explosion wave have been modeled in a tunnel, $25 \mathrm{~m}$ in depth. Then, Tunnel Stability will be studied in this depth. After primary modeling in UDEC, the drawn model will be solved because unbalancing powers should be zero (Figure 2).

After wave damping from explosion, developing plastic area, displacement cantores and speed variations are according to Figures 3-5.

Table 1. Mechanical specifications of rock mass and joints to model [2].

\begin{tabular}{cc}
\hline Mechanical Properties of Rocks & Mechanical Properties of Joints \\
\hline Dens: 0.002700 & Jkn: $10 \mathrm{e} 6$ \\
G: $3 \mathrm{e} 3$ & Jks: $10 \mathrm{e} 6$ \\
K: $5 \mathrm{e} 3$ & Jten: 100 \\
Ucs: 100 & Coh: 100 \\
Prat: 0.25 & Fric: 40 \\
Coh: 20 & Spacing: $30 \mathrm{~cm}=0.3 \mathrm{~m}$ \\
Fric: 25 & - \\
RMR $>90$ & - \\
\hline
\end{tabular}




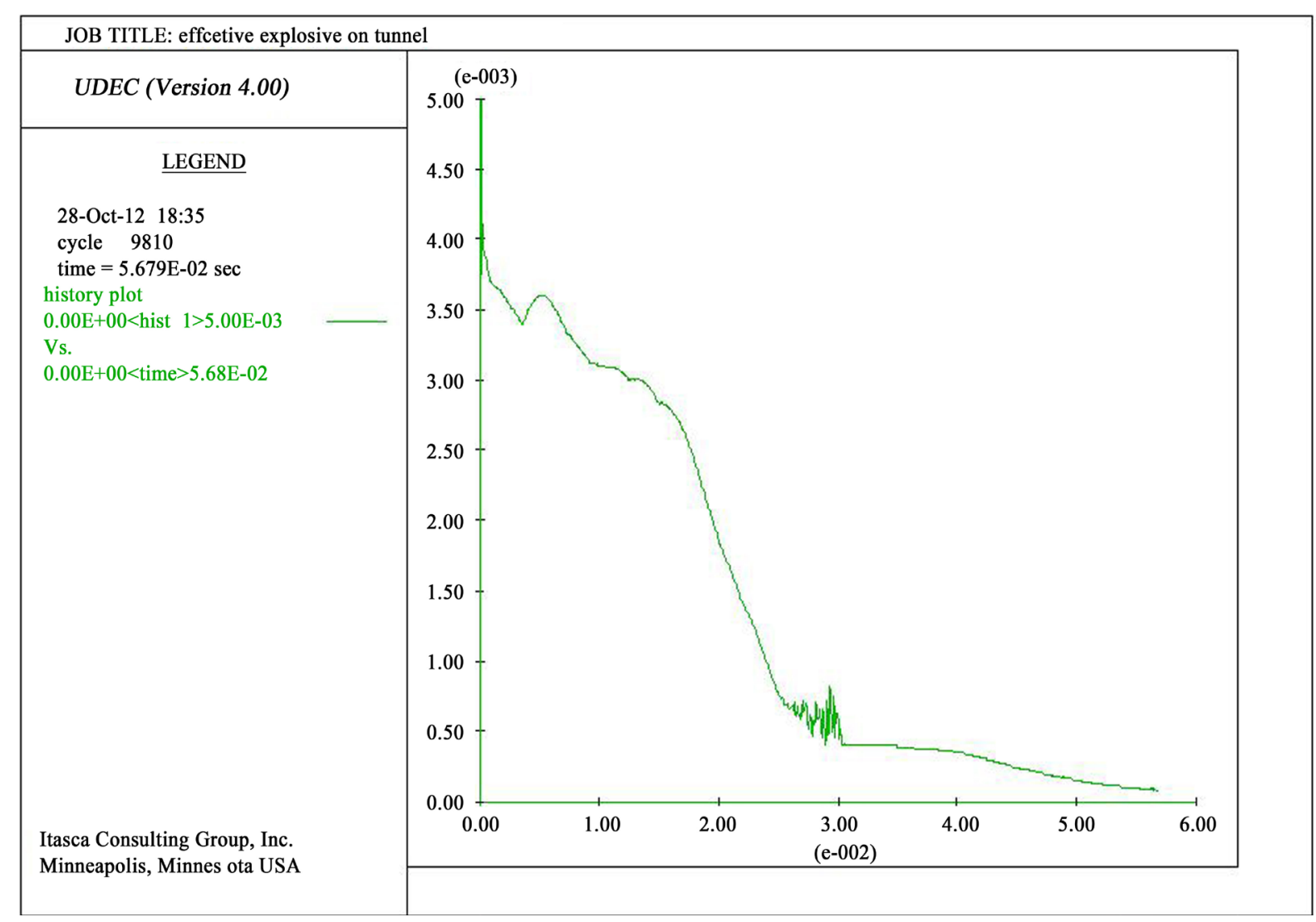

Figure 2. Variations of unbalancing powers in the model.

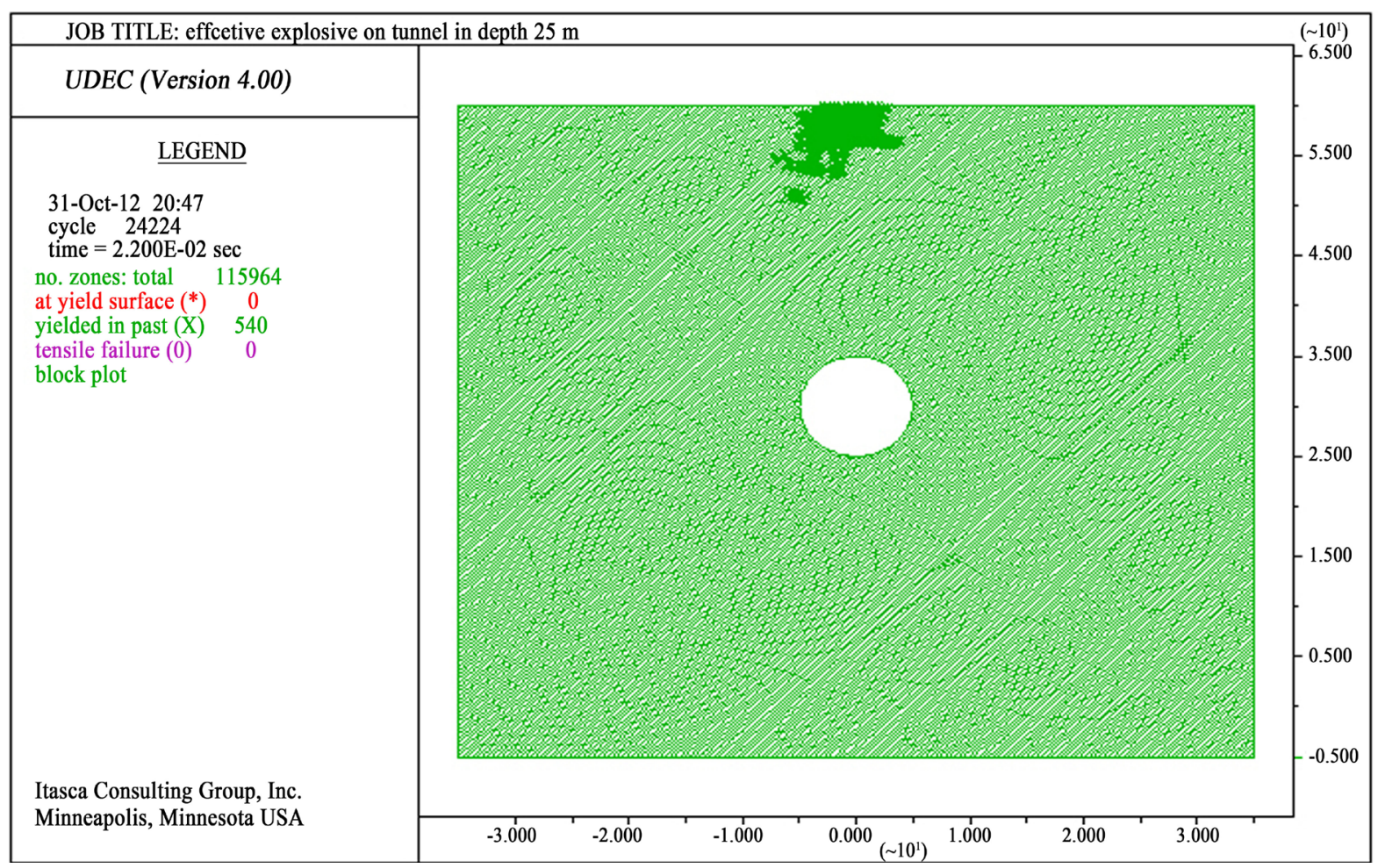

Figure 3. Developing a plastic area in a tunnel (depth: 25). 


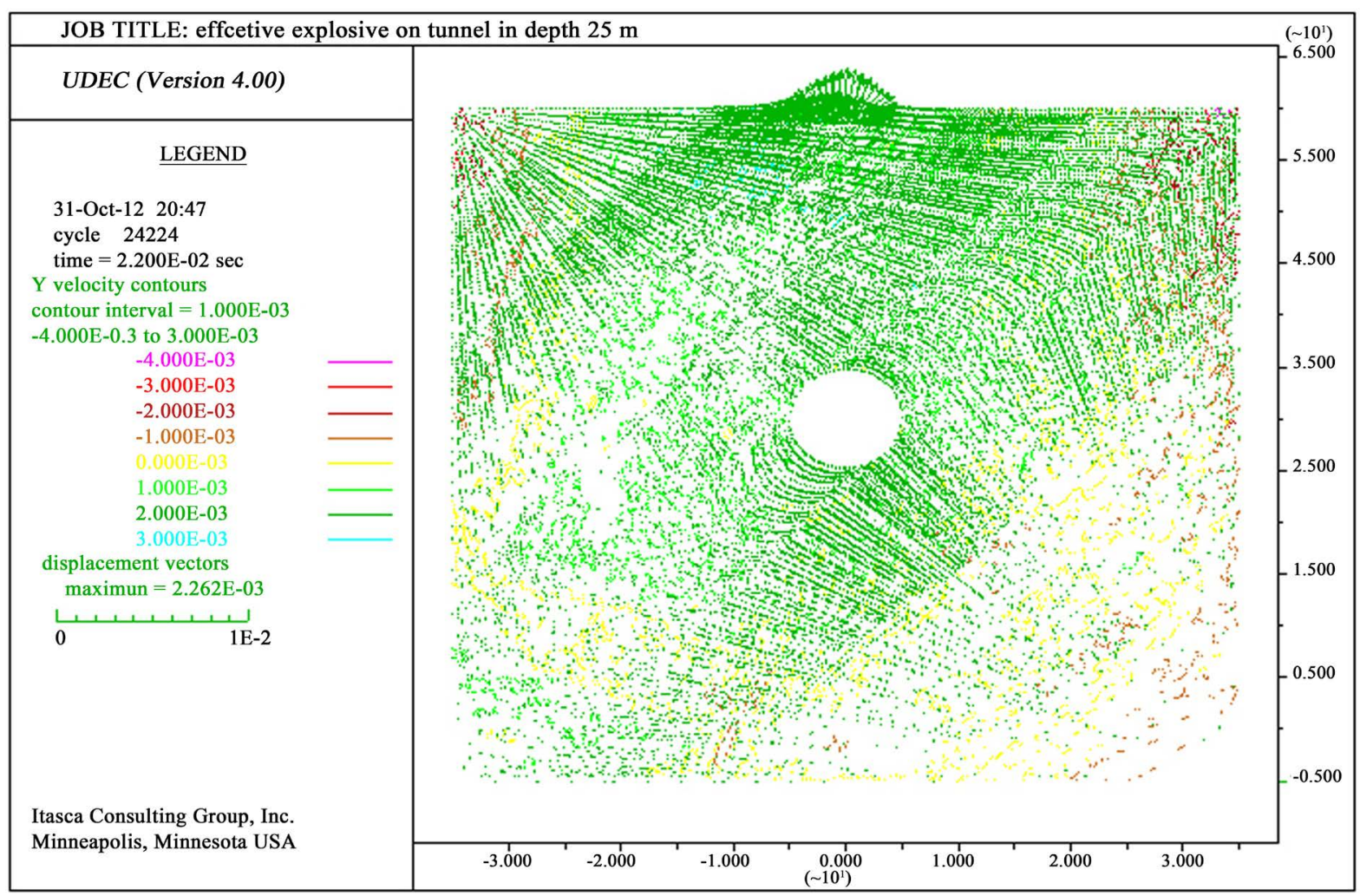

Figure 4. Displacement cantors variations in a tunnel (depth: 25).

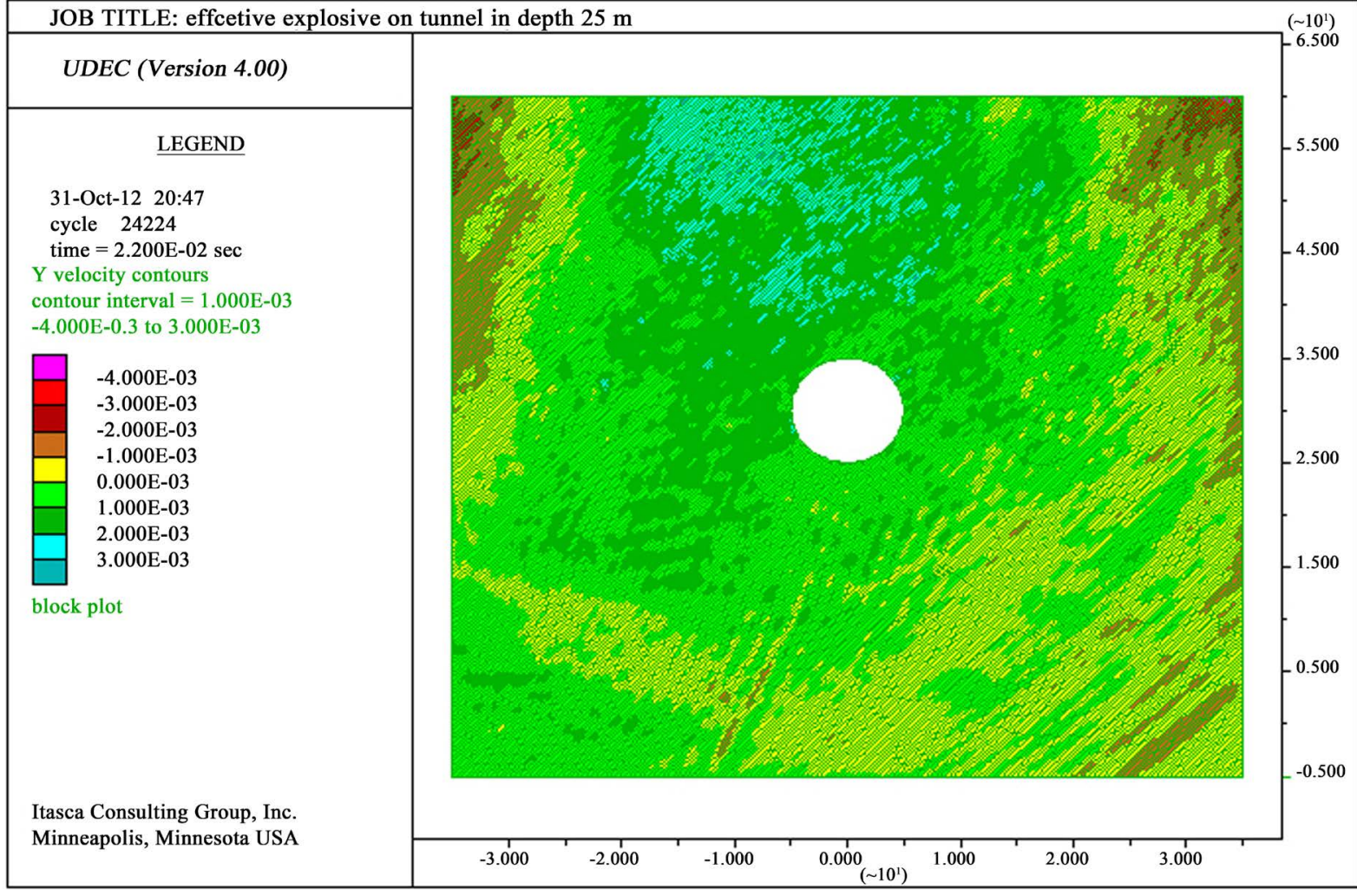

Figure 5. Cantors variations in a tunnel (depth: 25). 
Stress changes of the explosion in the ceiling, walls and floor of the tunnel is in accordance with the images below.

Stress in Crown of tunnel (Depth $25 \mathrm{~m}$ )

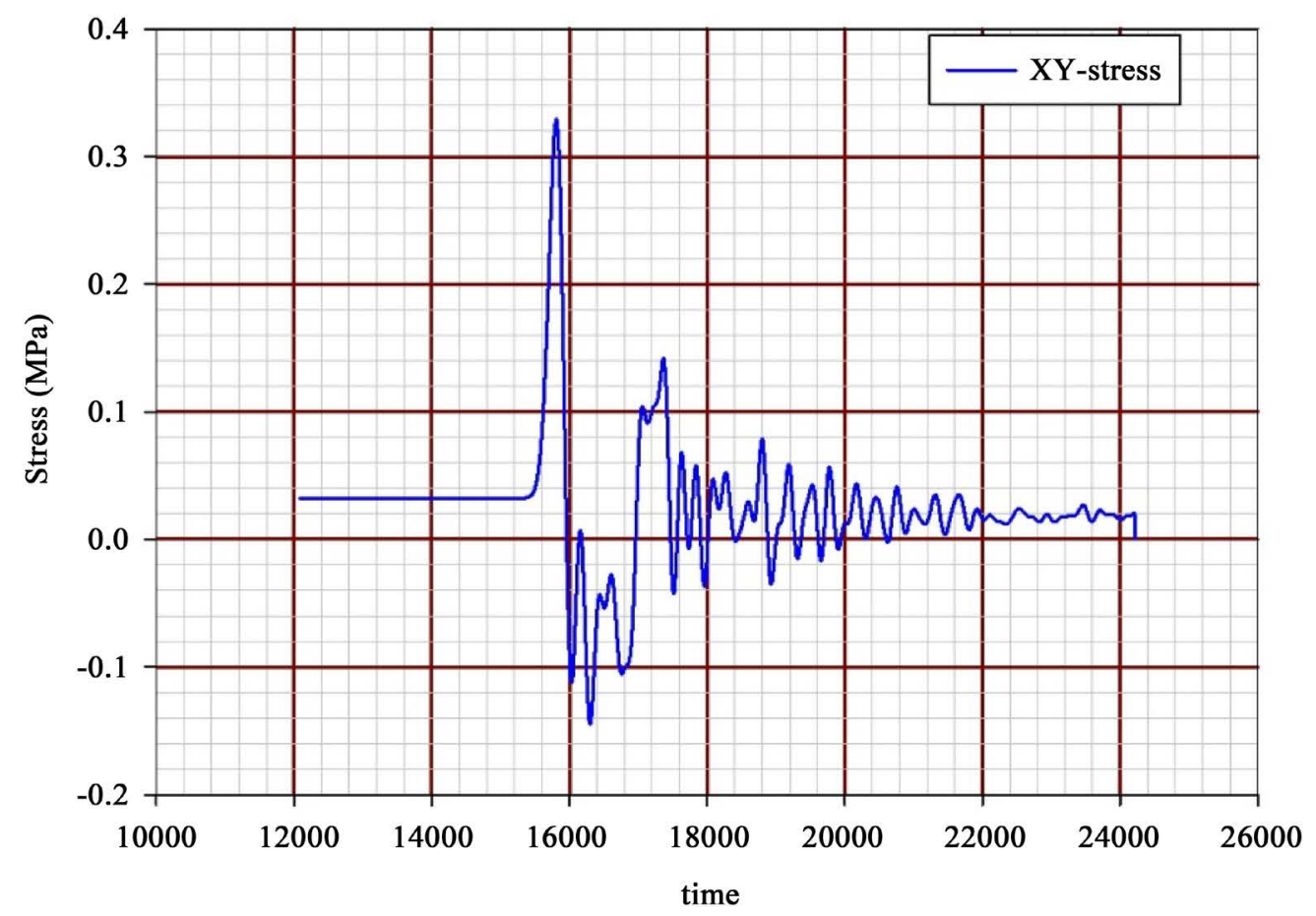

Stress in Bottom of tunnel (Depth $25 \mathrm{~m}$ )

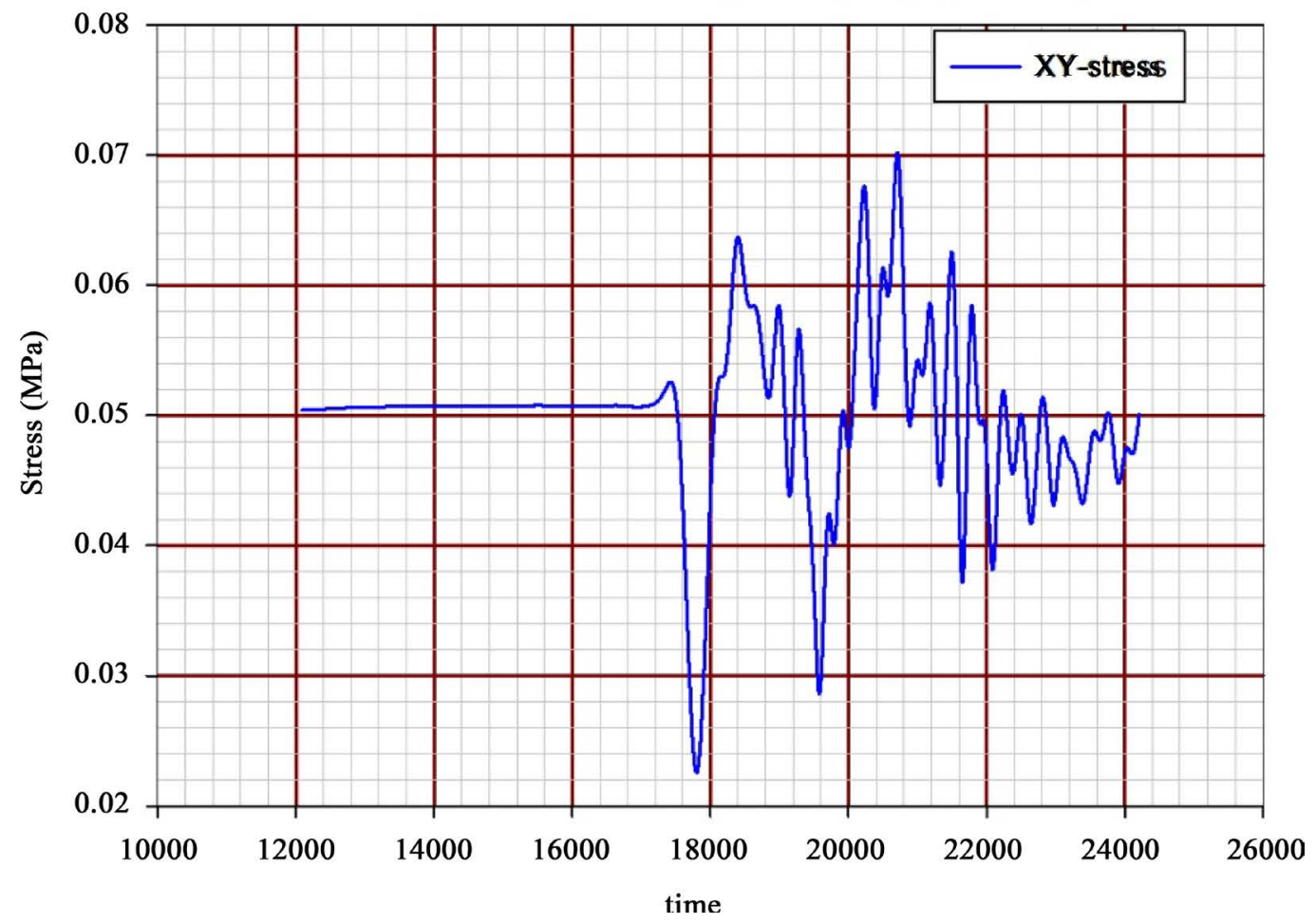


Stress in Right wall of tunnel (Depth $25 \mathrm{~m}$ )

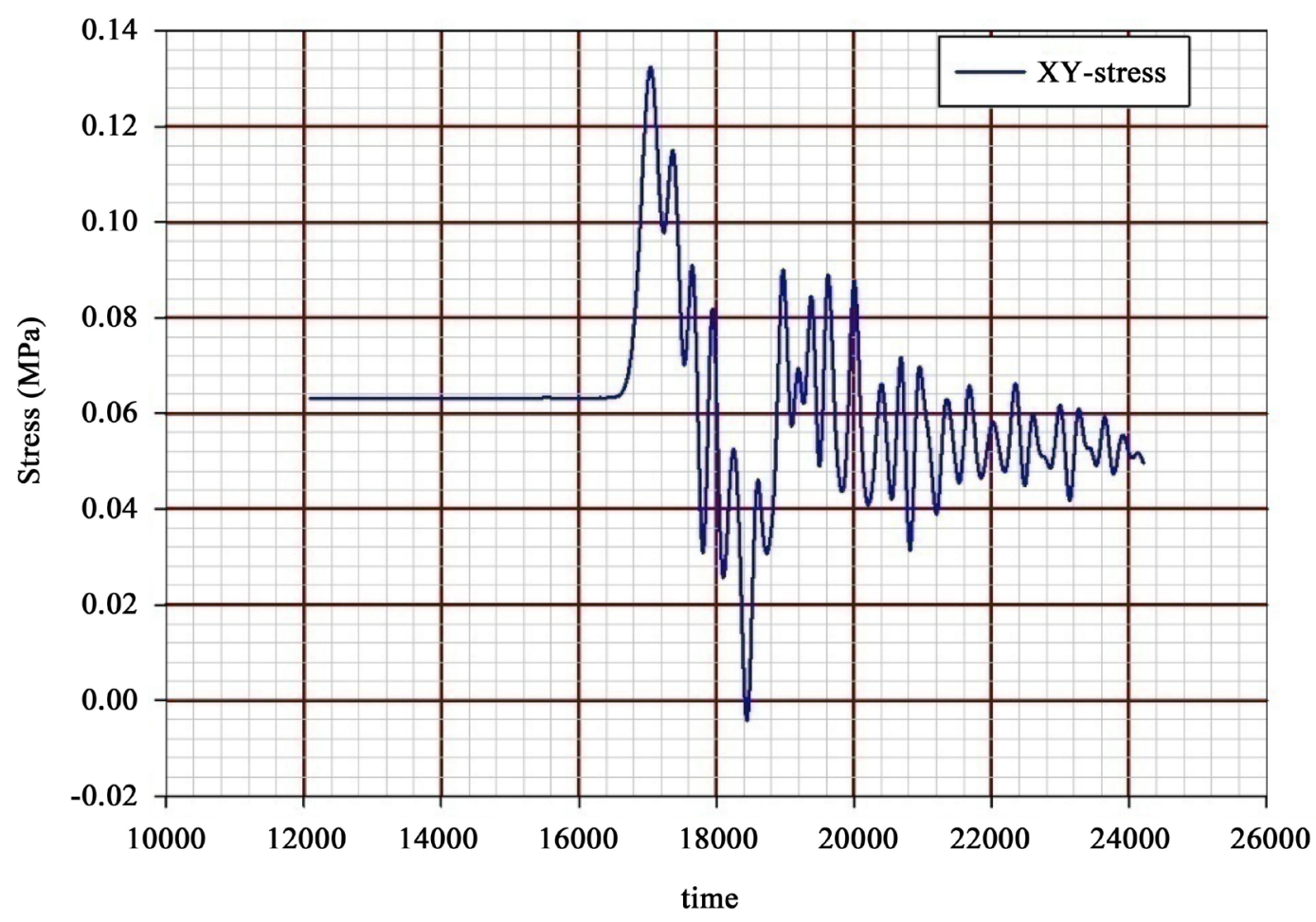

Stress in Left wall of tunnel (Depth $25 \mathrm{~m}$ )

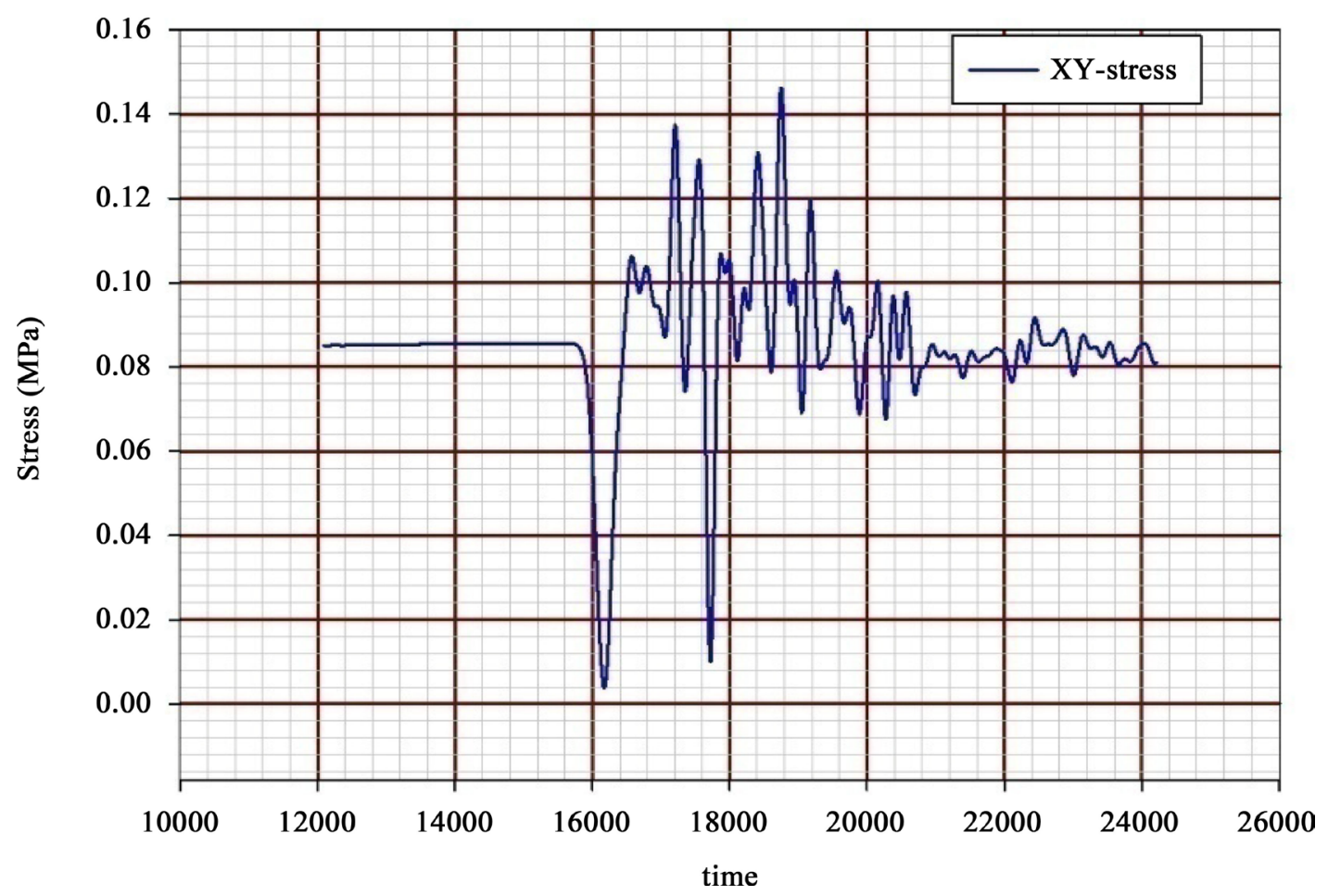


Following graph shows displacement variations (vertical and horizontal) in ceiling, walls and floor of tunnel, respectively.

\section{$X$-Displacement in Crown of tunnel (Depth $25 \mathrm{~m}$ )}

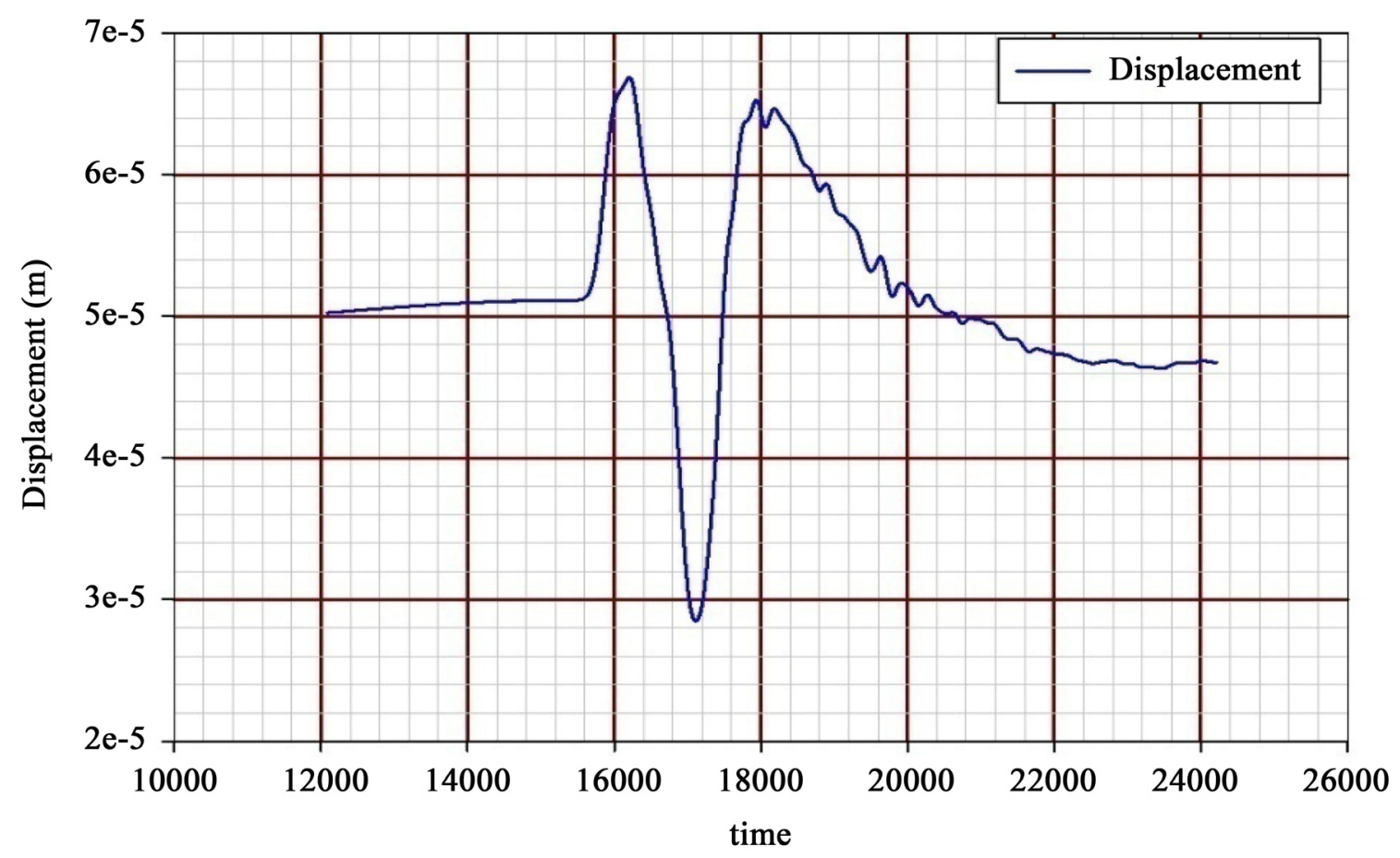

$X$-Displacement in Left wall of tunnel (Depth $25 \mathrm{~m}$ )

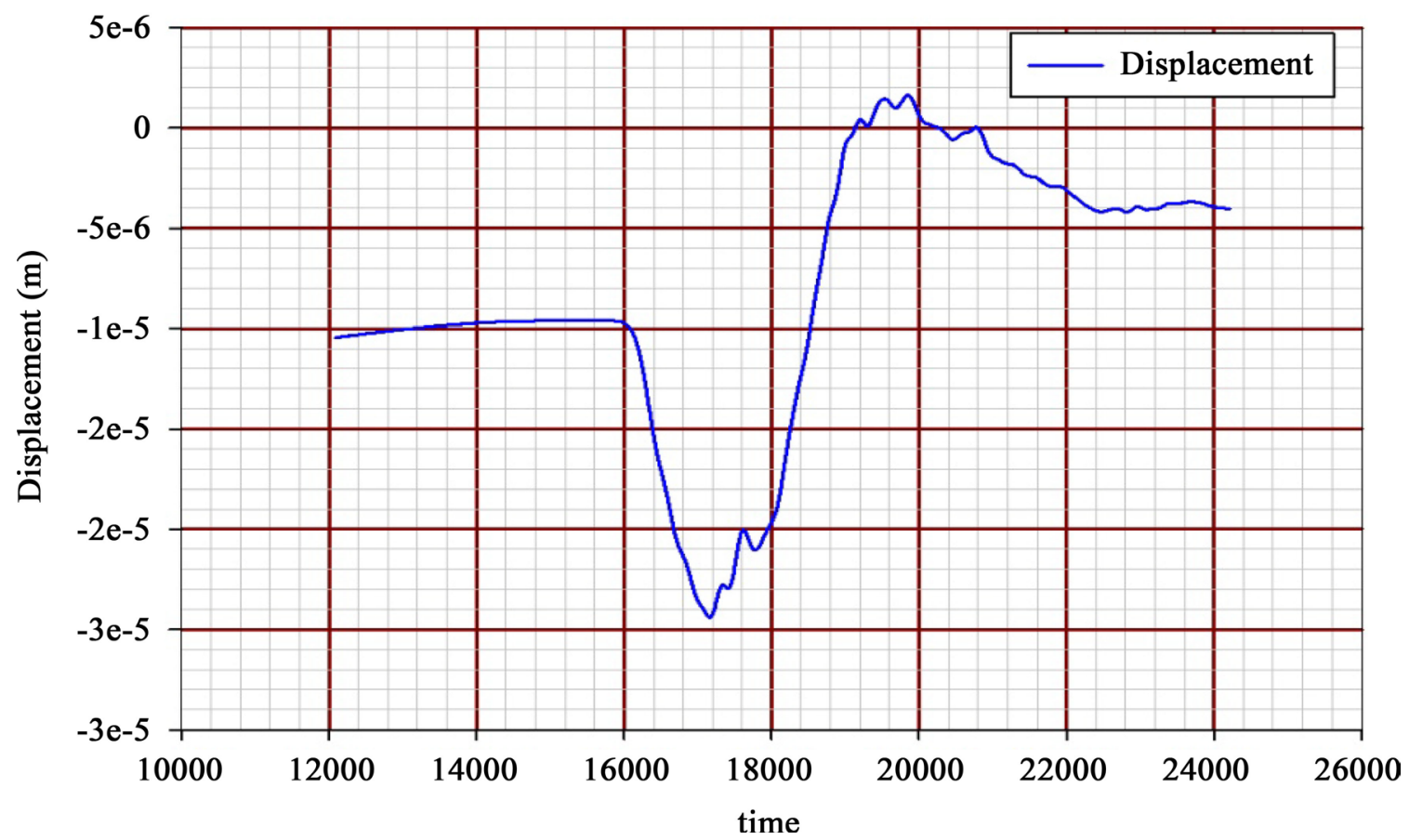




\section{$X$-Displacement in Bottom of tunnel (Depth $25 \mathrm{~m}$ )}

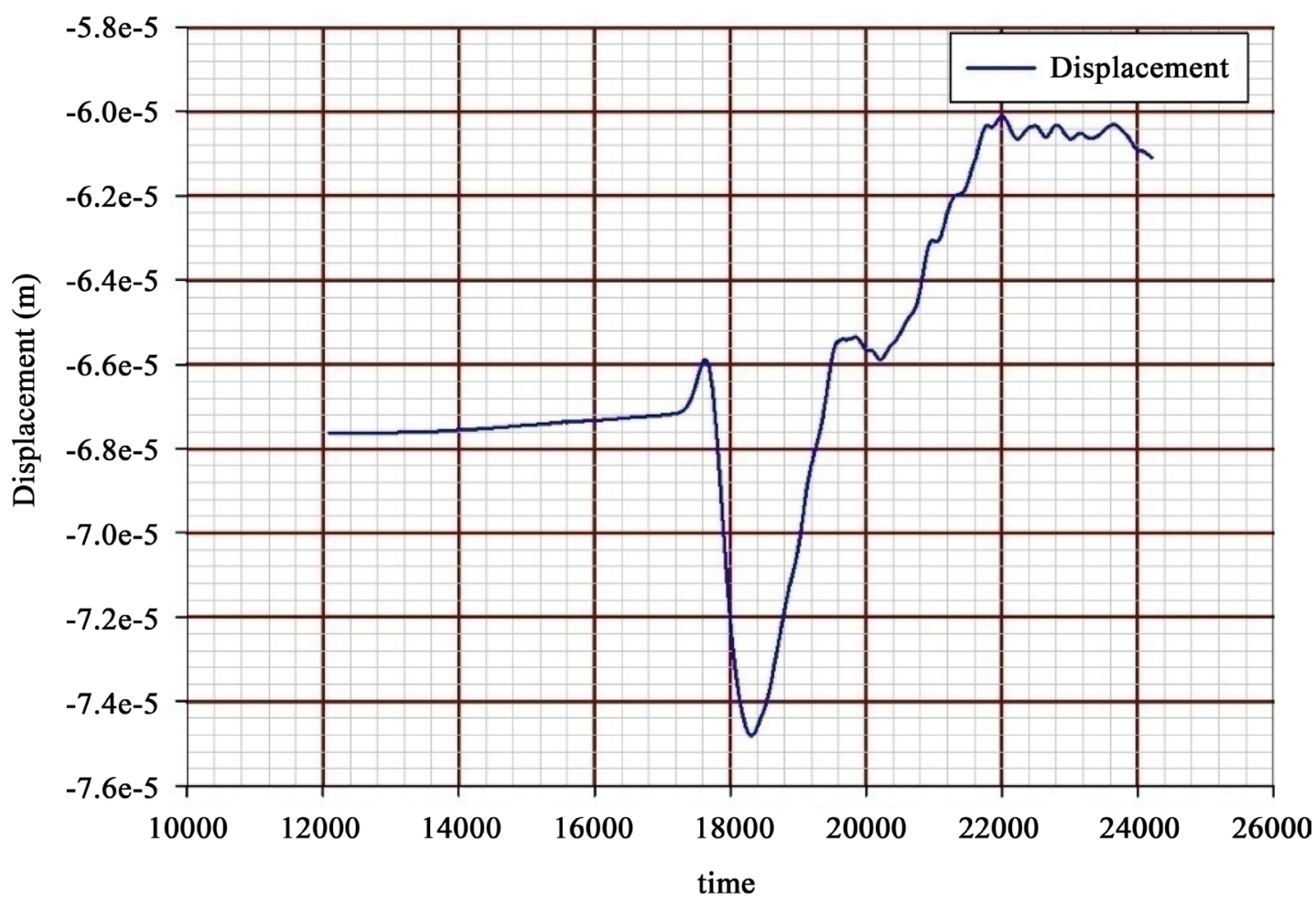

$X$-Displacement in Right wall of tunnel (Depth $25 \mathrm{~m}$ )

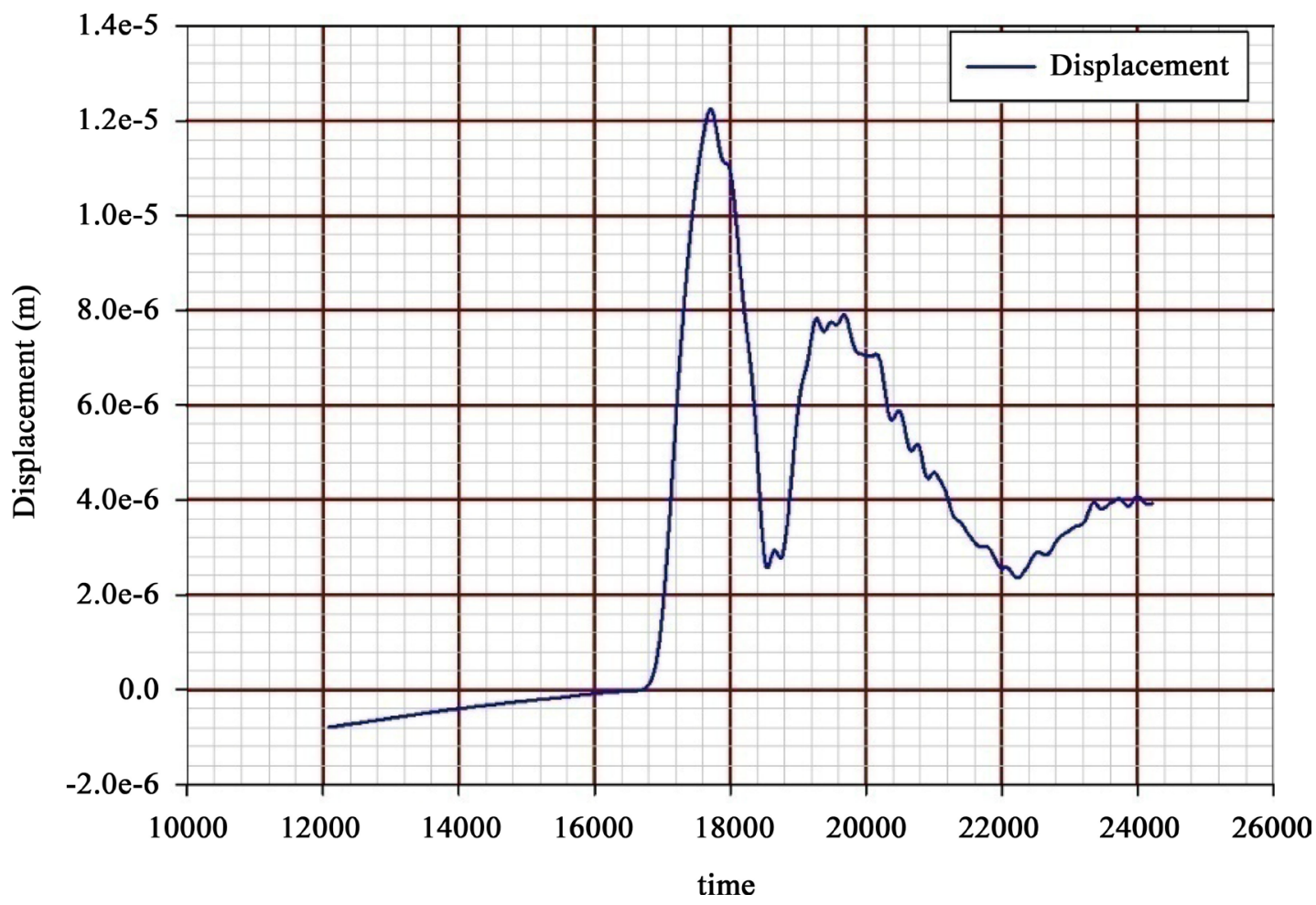




\section{Y-Displacement in Crown of tunnel (Depth $25 \mathrm{~m}$ )}

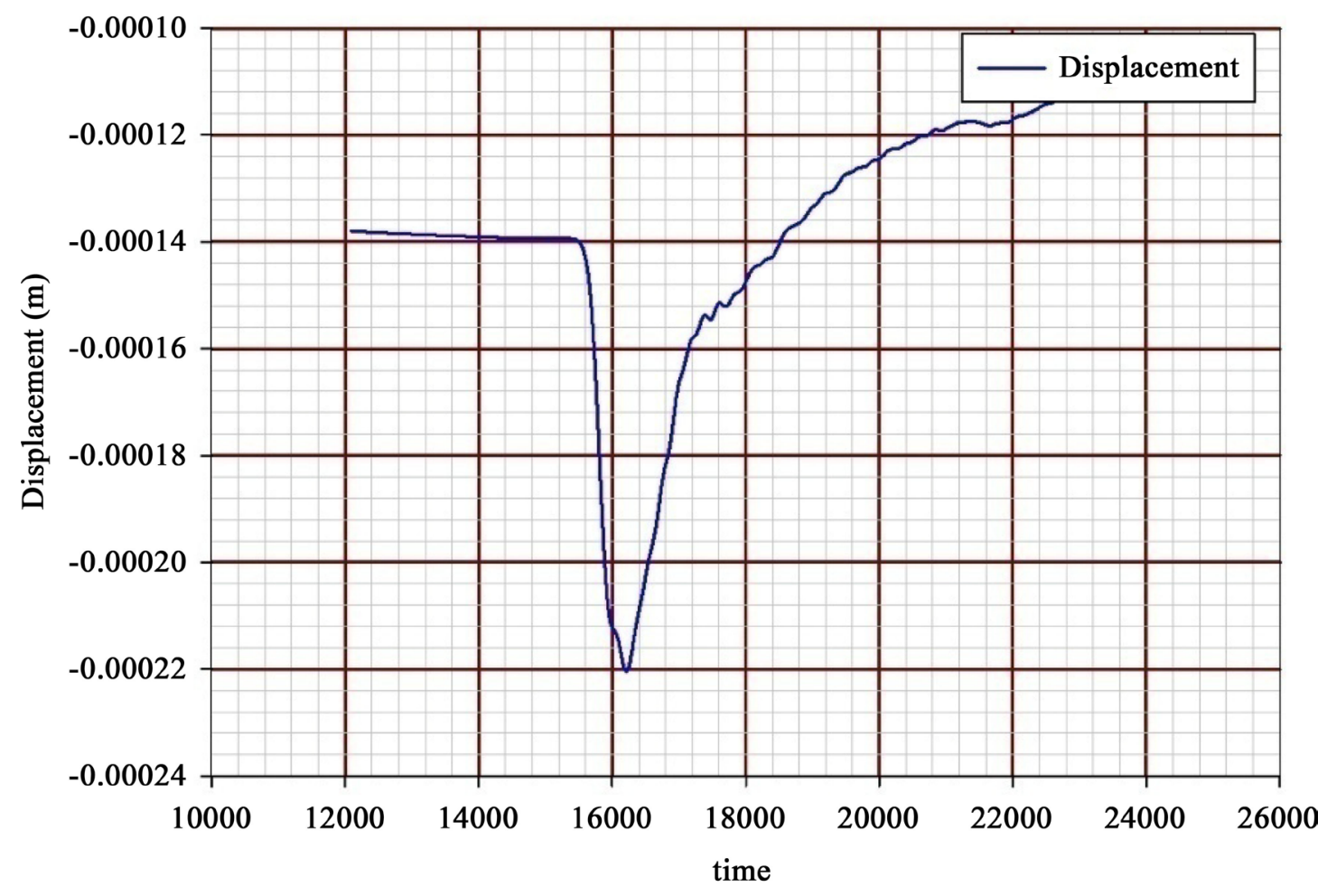

Y-Displacement in Left wall of tunnel (Depth $25 \mathrm{~m}$ )

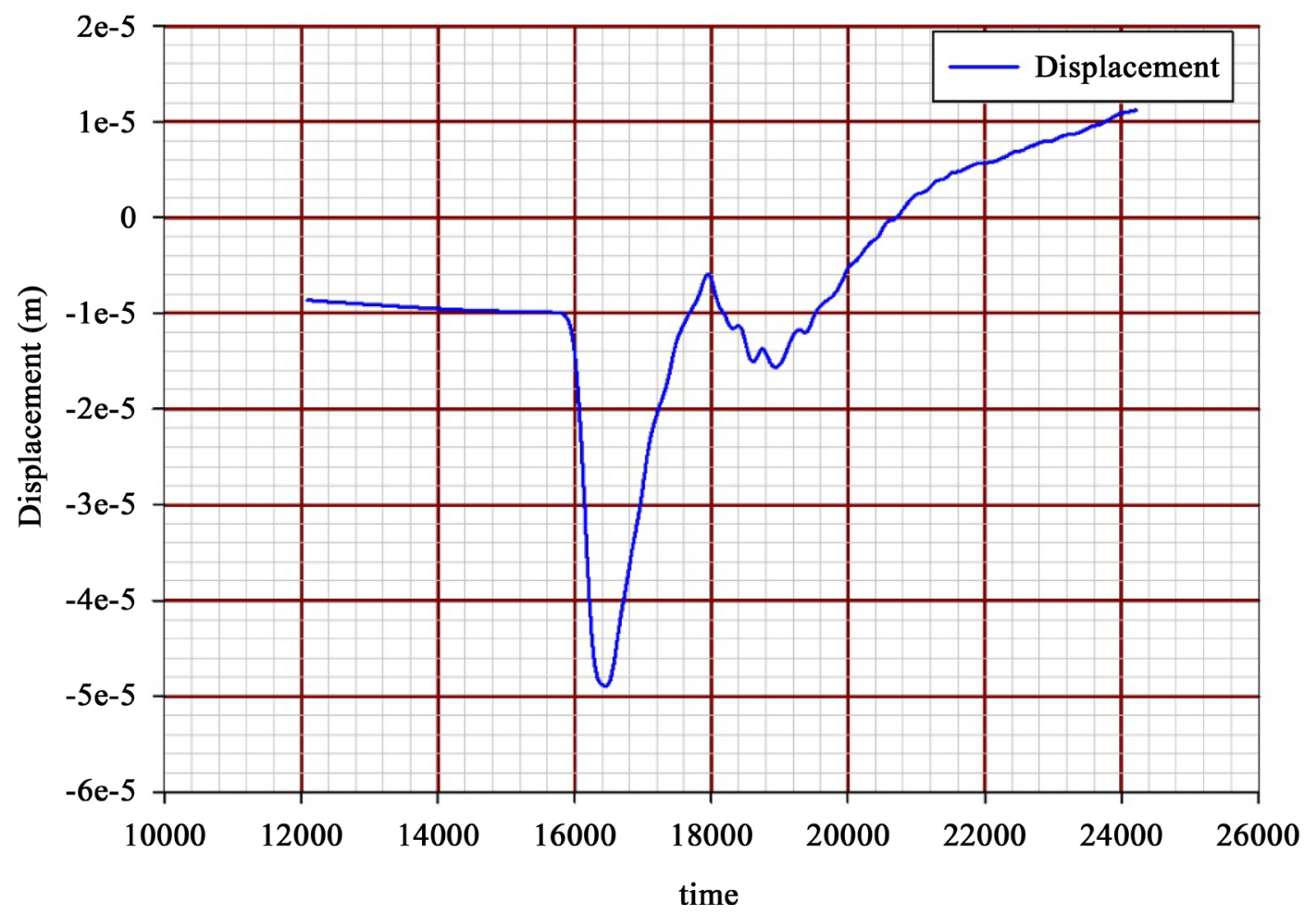




\section{Y-Displacement in Bottom of tunnel (Depth $25 \mathrm{~m}$ )}

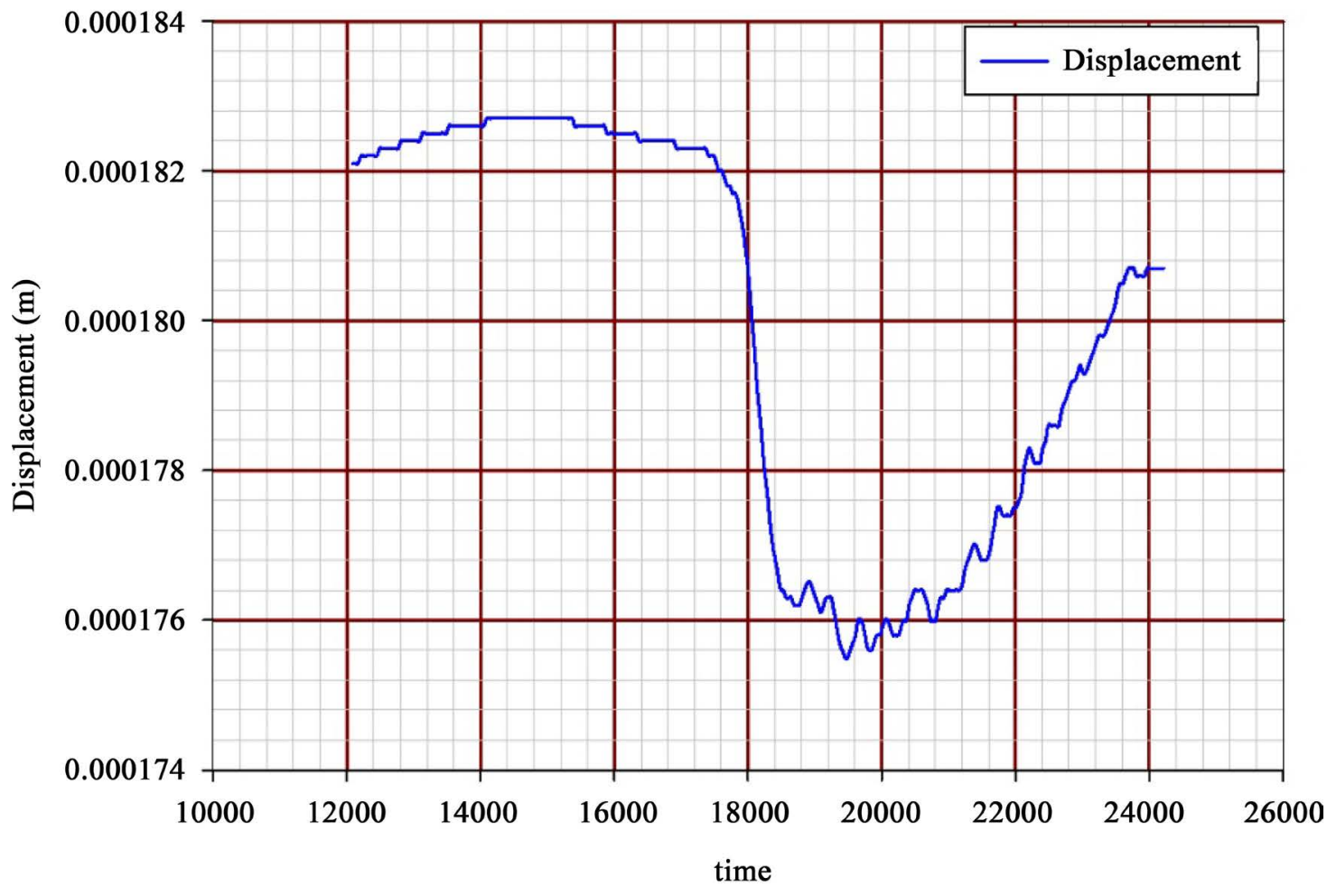

Y-Displacement in Right wall of tunnel (Depth $25 \mathrm{~m}$ )

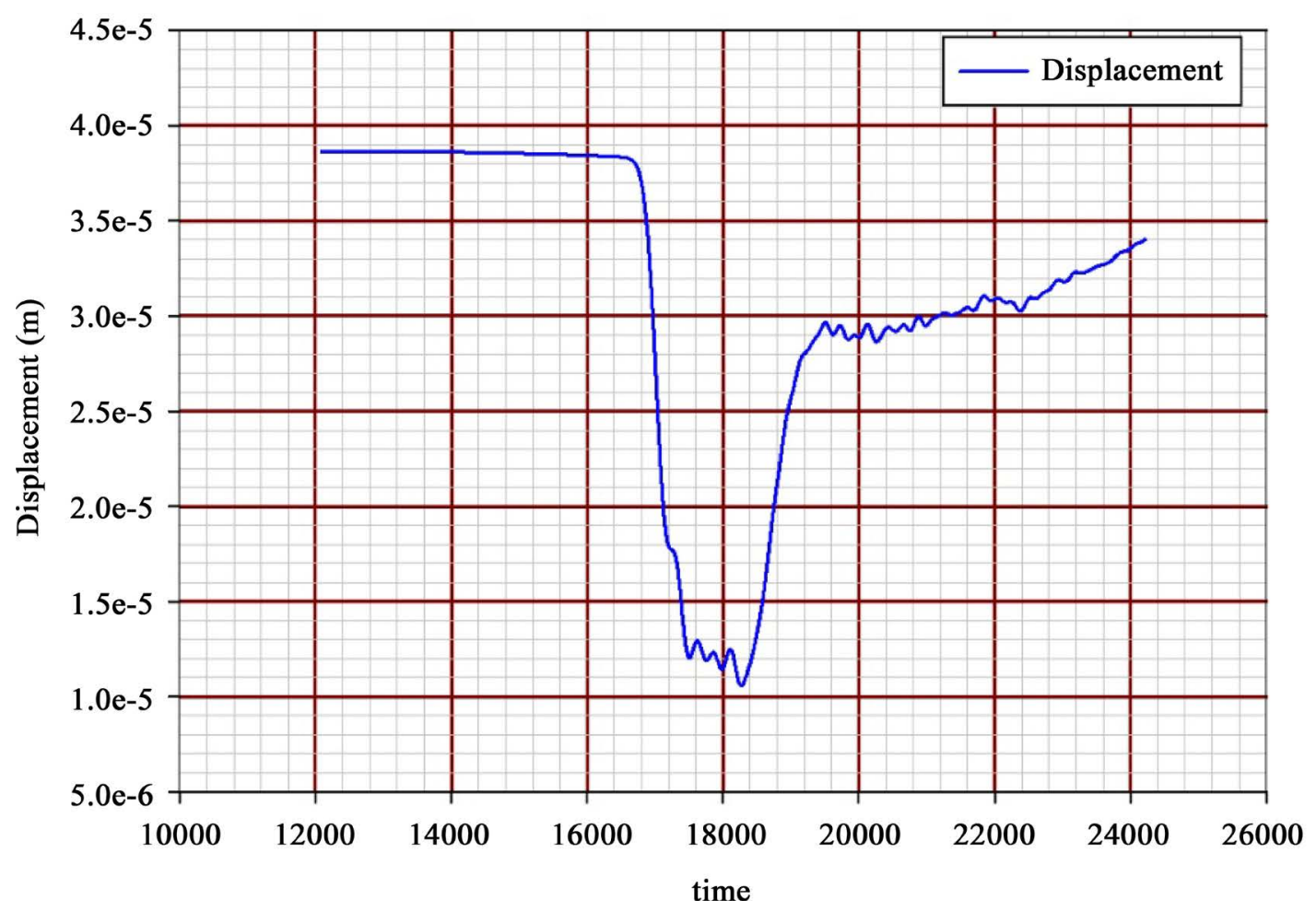


Displacement from an explosion in a tunnel (depth: 25)

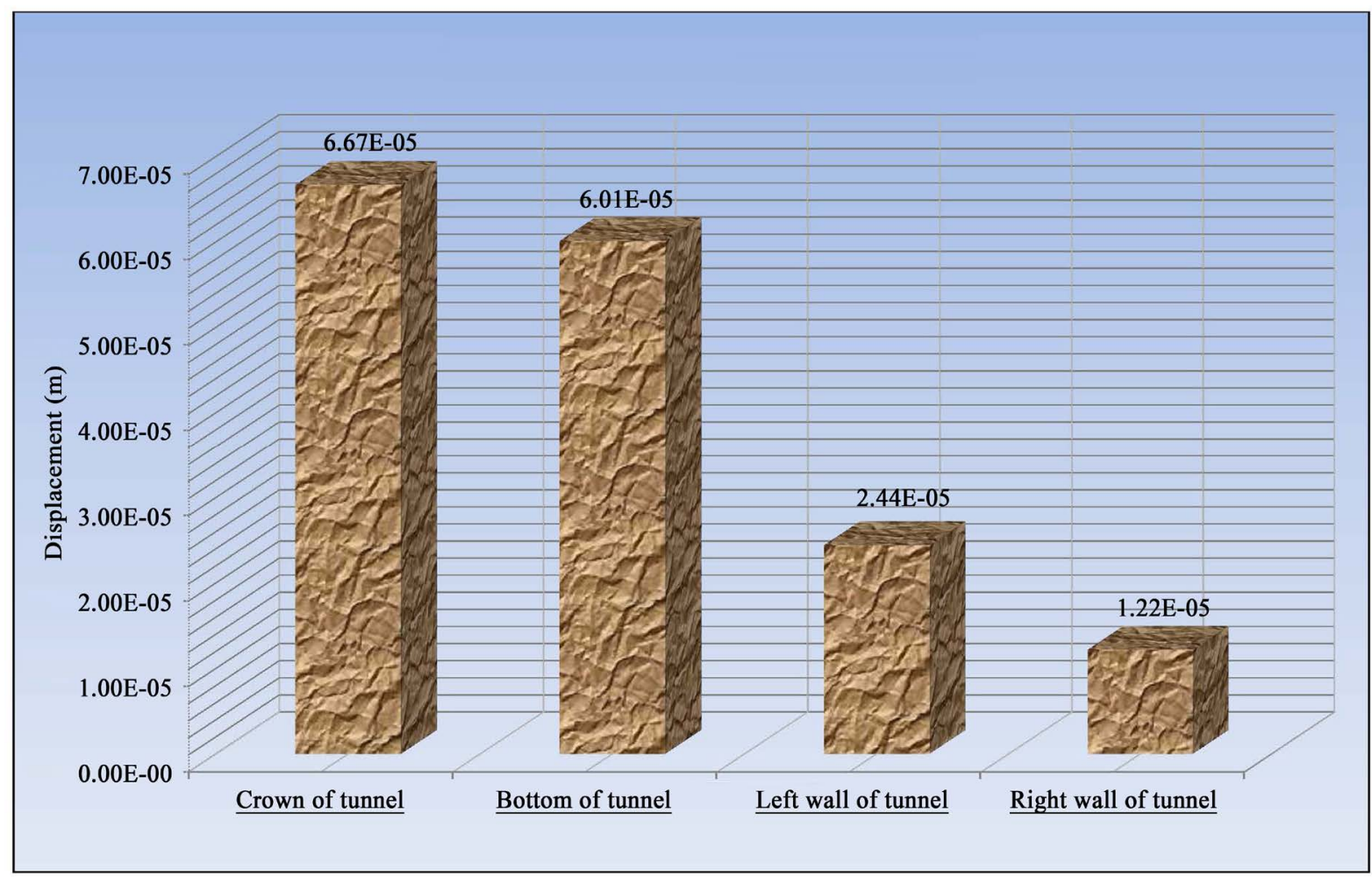

Horizontal Displacement

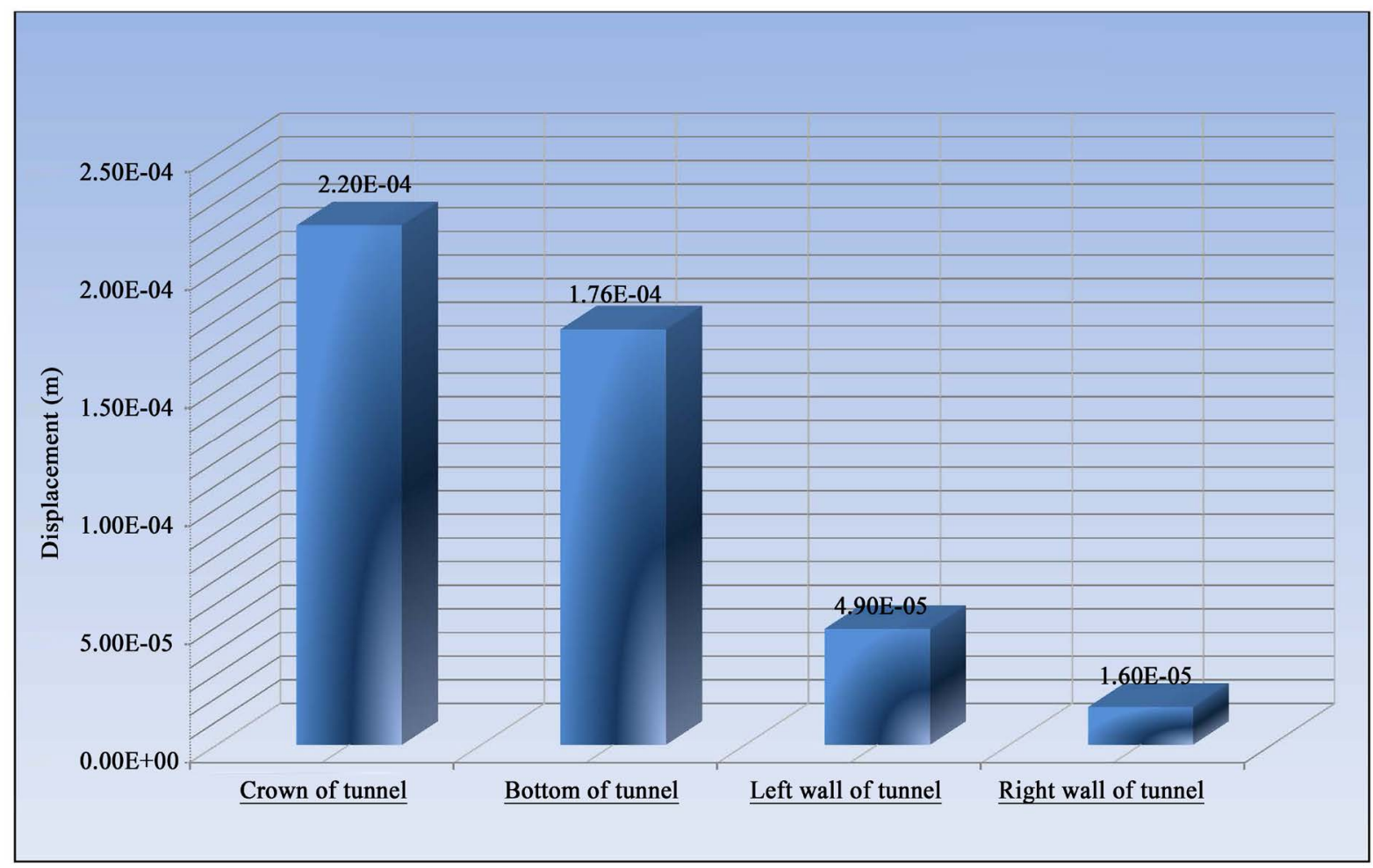

Vertical Displacement 


\section{Conclusions}

Results from this modeling are as following:

1) Developing is limited in depth of $15 \mathrm{~m}$.

2) Minimum overload altitude is $20 \mathrm{~m}$ for underground structure to resist against explosion.

3) Optimal depth and stability of a tunnel is more than $25 \mathrm{~m}$ regarding this rock mass.

4) Studying on Tunnel Behaviors such as displacement and strain on the ceiling indicate that the tunnel will be stable if it is placed in every depth and under dynamical load equal to 10 Tons TNT but optimal depth to drill a tunnel with minimum strain is $20-30 \mathrm{~m}$.

\section{References}

[1] Smith, P.D. (1994) Blasting and Ballistic Loading of Structures. Butterworth-Heineman Ltd.

[2] Arab, M.R. and Mirzeynali, S.H. (2001) Numerical Modeling of Explosive Loading on Strong Rock Mass with Discontinuity System. Malek Ashtar Industry University.

[3] Yang, S.T. and Cao, Z.Y. (1983) An Analytical Solution for Underground Structure Rock-Dynamic Interaction. Applied Mathematics \& Mechanics, 4.

[4] Chen, S.G. and Zhao, J. (1998) A Study of UDEC Modeling for Blast Wave Propagation in Jointed Rock Masses. International Journal of Rock Mechanics and Mining Sciences, 35, 93-99. http://dx.doi.org/10.1016/S0148-9062(97)00322-7

[5] Morris, J.P., Rubin, M.B., Blair, S.C., Glenn, L.A. and Heuze, F.E. (2004) Simulations of Underground Structures Subjected to Dynamic Loading Using the Distinct Element Method. Engineering Computations, 21, 384-408. http://dx.doi.org/10.1108/02644400410519848

[6] Lu, Y. (2005) Underground Blast Induced Ground Shock and Its Modeling Using Artificial Neural Network. Journal of Computers and Geotechnics, 32, 164-178. http://dx.doi.org/10.1016/j.compgeo.2005.01.007

[7] Heuze, F.E. and Morris, J.P. (2006) Insights into Ground Shock in Jointed Rocks and the Response of Structures There-In. International Journal of Rock Mechanics and Mining Sciences, 44, 647-676. http://dx.doi.org/10.1016/j.ijrmms.2006.09.011

[8] Jiao, Y.Y., Zhang, X.L., Zhao, J. and Liu, Q.S. (2007) Viscous Boundary of DDA for Modeling Stress Wave Propagation in Jointed Rock. International Journal of Rock Mechanics and Mining Sciences, 44, 1070-1076. http://dx.doi.org/10.1016/j.ijrmms.2007.03.001

[9] Mortazavi, A. (2008) Numerical Analysis of Strength Properties of Discontinues on Stability of Underground Spaces under Dynamic Load. The Sixth Tunnel Conference, Civil Engineering College of Tehran Science and Indust University.

[10] Bajarivalam, H. and Mirzeynali, S.H. (2010) Modeling of Explosive Loading on Weak Rock Mass with Continuity System. Malek Ashtar Industry University.

[11] TM 5-1300 (UFC 3-340-02) US (1990) Army Corps of Engineers, Structures to Resist the Effects of Accidental Explosions. US Army Corps of Engineers, Washington DC. 